\title{
Xanthomonas axonopodis Virulence Is Promoted by a Transcription Activator-Like Effector-Mediated Induction of a SWEET Sugar Transporter in Cassava
}

\author{
Megan Cohn, ${ }^{1}$ Rebecca S. Bart, ${ }^{1}$ Mikel Shybut, ${ }^{1}$ Douglas Dahlbeck, ${ }^{1}$ Michael Gomez, ${ }^{1}$ \\ Robert Morbitzer, ${ }^{2}$ Bi-Huei Hou, ${ }^{3}$ Wolf B. Frommer, ${ }^{3}$ Thomas Lahaye, ${ }^{2}$ and Brian J. Staskawicz ${ }^{1}$ \\ ${ }^{1}$ Department of Plant and Microbial Biology, 111 Koshland Hall, University of California, Berkeley 94720-3120, U.S.A.; \\ ${ }^{2}$ ZMBP-General Genetics, University of Tübingen, Auf der Morgenstelle 32, D-72076, Tübingen, Germany; ${ }^{3}$ Department of \\ Plant Biology, Carnegie Institution for Science, 260 Panama Street, Stanford, CA 94114, U.S.A.
}

Submitted 2 June 2014. Accepted 4 July 2014.

\begin{abstract}
The gene-for-gene concept has historically been applied to describe a specific resistance interaction wherein single genes from the host and the pathogen dictate the outcome. These interactions have been observed across the plant kingdom and all known plant microbial pathogens. In recent years, this concept has been extended to susceptibility phenotypes in the context of transcription activator-like (TAL) effectors that target SWEET sugar transporters. However, because this interaction has only been observed in rice, it was not clear whether the gene-for-gene susceptibility was unique to that system. Here, we show, through a combined systematic analysis of the TAL effector complement of Xanthomonas axonopodis pv. manihotis and RNA sequencing to identify targets in cassava, that TAL20 Xam668 specifically induces the sugar transporter MeSWEET10a to promote virulence. Designer TAL effectors (dTALE) complement TAL20 Xam668 mutant phenotypes, demonstrating that MeSWEET10a is a susceptibility gene in cassava. Sucrose uptake-deficient $X$. axonopodis pv. manihotis bacteria do not lose virulence, indicating that sucrose may be cleaved extracellularly and taken up as hexoses into $X$. $a x$ onopodis pv. manihotis. Together, our data suggest that pathogen hijacking of plant nutrients is not unique to rice blight but also plays a role in bacterial blight of the dicot cassava.
\end{abstract}

Xanthomonas axonopodis pv. manihotis, the causal agent of bacterial blight of cassava, delivers type III effector proteins into the plant cell to suppress or modulate host innate immunity and promote pathogenesis. Most X. axonopodis pv. manihotis strains studied to date contain between one and five transcription activator-like (TAL) effectors (Bart et al. 2012; Castiblanco et al. 2013) which, in other xanthomonads, have been shown to elicit disease symptoms by inducing expression of host genes that allow the pathogen to achieve full

M. Cohn and R. S. Bart contributed equally to this work.

Corresponding author: Brian J. Staskawicz; E-mail stask@berkeley.edu; Telephone +1.510.642.3721.

* The $\boldsymbol{e}$-Xtra logo stands for "electronic extra" and indicates that seven supplementary figures, three supplementary tables, and supplementary methods information are published online.

(C) 2014 The American Phytopathological Society virulence (Antony et al. 2010; Cernadas et al. 2014; Hu et al. 2014; Li et al. 2014; Verdier et al. 2012; Yang et al. 2006). TAL effectors are delivered into host cells via the Xanthomonas type III secretion system and are translocated to the plant nucleus, where they physically interact with DNA in a sequence-specific manner to activate host gene expression (Boch and Bonas 2010; Bogdanove et al. 2010; Deng et al. 2012; Kay et al. 2007; Mak et al. 2012; Römer et al. 2007). Consistent with their function, the modular structure of TAL effectors consists of an N-terminal type III secretion signal, Cterminal nuclear-localization sequences, eukaryotic acidic activation domain, and central repeat domain that are responsible for sequence-specific protein-DNA interactions. This central repeat domain consists of a variable number of 33 to 35 amino acid repeats which are nearly identical, with most polymorphism residing at amino acids 12 and 13, known as the repeat variable diresidues (RVD). The amino acid identity of these RVD dictates the TAL effector-DNA-binding code, with each RVD specifying the binding of a single consecutive nucleotide through direct interaction (Boch et al. 2009; Moscou and Bogdanove 2009). Structural studies have shown that residue 13 in each repeat makes specific contact with the DNA, while residue 12 plays a stabilizing role (Deng et al. 2012; Mak et al. 2012). The nucleotide sequence bound by TAL effectors is called the effector-binding element (EBE).

TAL effectors can function either in effector-triggered immunity (ETI) if recognized by resistance $(R)$ genes or as virulence determinants activating plant genes whose increased or ectopic expression facilitates bacterial growth, disease symptom formation, or both (Schornack et al. 2013). Several TAL effector-targeted genes have been identified as susceptibility genes, providing insight into strategies used by Xanthomonas during infection. UPA20, activated by the TAL effector AvrBs3 from $X$. euvesicatoria, is a transcription factor that regulates cell size in pepper (Capsicum annuum), leading to the cell hypertrophy that is a symptom of infection by $X$. euvesicatoria (Kay et al. 2007). CsLOB1, a transcription factor in sweet orange (Citrus sinensis) associated with expression of genes involved in cell expansion, is activated by multiple TAL effectors of $X$. citri subsp. citri. Expression of $C S L O B 1$ promotes citrus bacterial canker pustule formation and in planta bacterial growth (Hu et al. 2014; Li et al. 2014). TAL2g of the rice (Oryza sativa) mesophyll colonizer $X$. oryzae pv. oryzicola activates the predicted sulfate transporter OSSULTR3;6 to promote lesion expansion and bacterial exudation from the leaf

1186 / Molecular Plant-Microbe Interactions 
surface (Cernadas et al. 2014). OsSWEET11 and OsSWEET14 from rice, each activated by at least one $X$. oryzae pv. oryzae TAL effector, are members of the SWEET family of sugar transporters and were shown to transport both glucose and sucrose (Antony et al. 2010; Chen et al. 2010, 2012; Yang et al. 2006). Expression of host SWEET transporters at the site of bacterial infection is thought to cause an excess of sucrose to be transported into the apoplasm, providing bacteria with a source of carbon (Chen 2014).

The recessive rice resistance gene $x a 13$ was found to be an allele of OSSWEET11 that contains a modified promoter sequence that can neither be bound nor activated by the TAL effector PthXo1, rendering strains that utilize PthXo1 as their primary determinant of virulence unable to cause disease (Chu et al. 2006; Yang et al. 2006). A second recessive rice resistance gene, $x a 25$, encodes OsSWEET13 and is thought to avoid targeting by an as of yet unidentified TAL effector in a similar manner (Liu et al. 2011; Yuan and Wang 2013). Inspired by naturally occurring plant alleles, researchers have shown that plant disease resistance can be engineered by employing genome editing technologies to manipulate EBE in the promoters of susceptibility genes, such that they can no longer be activated in a TAL effector-dependent manner $(\mathrm{Li}$ et al. 2012). Engineering recessive resistance by modifying host susceptibility gene promoters is a strategy that could be combined (stacked) with dominant $R$-gene-mediated strategies employed by breeders and researchers (Schornack et al. 2013). However, in order to be a widely applicable strategy, susceptibility targets must first be identified in the pathosystem of interest.

Cassava (Manihot esculenta) is a root crop grown in Africa, Asia, and South America and is the third most important source of calories for people living in the tropics behind rice and corn (FAO 2008). Cassava production is increasing in part because of the low input costs and drought tolerance of this staple food source. However, cassava remains a relatively understudied crop (Howeler et al. 2013). Outbreaks of cassava bacterial blight (CBB), incited by $X$. axonopodis pv. manihotis, can cause extensive crop damage and constrain production (López and Bernal 2012; Lozano 1986). CBB symptoms include watersoaked angular lesions on leaves, shoot dieback, and necrosis. The development of resistant cassava varieties could protect farmers from the crop losses associated with CBB (Wydra et al. 2004). A robust cassava transformation protocol has been developed which will allow genetic engineering approaches to address this problem (Bull et al. 2009). However, few reports of phenotypic resistance to $\mathrm{CBB}$ exist and the genes underlying resistance have not been extensively studied, resulting in a lack of resources for genetic engineering of resistant cultivars (López and Bernal 2012). In addition, efforts at attaining CBB resistance through breeding have been largely unsuccessful, most likely due to genetic diversity among $X$. axonopodis $\mathrm{pv}$. manihotis strains (Bart et al. 2012; Restrepo et al. 2000, 2004). All sequenced $X$. axonopodis pv. manihotis strains contain TAL effector-like sequences, indicating that TAL effectors are a conserved component of $X$. axonopodis pv. manihotis's virulence arsenal (Arrieta-Ortiz et al. 2013; Bart et al. 2012). In addition, Castiblanco and associates (2013) demonstrated a virulence role for TALE1 $1_{\mathrm{Xam}}$ from $X$. axonopodis pv. manihotis CFBP1851. Therefore, the development of resistance based on modification of TAL effector susceptibility targets in the plant is a promising approach to developing cassava that is resistant to $\mathrm{CBB}$.

In this study, we characterize the TAL effectors of highly virulent $X$. axonopodis pv. manihotis Xam668 and identify TAL14 ${ }_{\text {Xam668 }}$ and TAL20 ${ }_{\text {Xam668 }}$ as important contributors to $X$. axonopodis pv. manihotis virulence. We use RNA sequencing
(RNA-Seq) to identify host gene targets for all TAL effectors of Xam668, and identify a SWEET sugar transporter, MeSWEET10a, that is directly activated by TAL20 Xam668. We use designer TAL effectors (dTALE) to show that MeSWEET10a is the primary virulence target of TAL20 Xam668.

\section{RESULTS}

\section{Xam668 TAL effectors contribute unequally} to virulence and symptom development.

To assess the role of TAL effectors in $X$. axonopodis pv. manihotis virulence, we generated mutant strains for each of the five TAL effectors present in virulent $X$. axonopodis pv. manihotis Xam668. The Xam668 TAL effector RVD sequences were published previously (Bart et al. 2012). We subsequently identified two additional repeat units present in TAL18 ${ }_{\text {Xam668, }}$, henceforth referred to as TAL20 ${ }_{\text {Xam668 }}$ (Supplementary Table S1) (Bart et al. 2013). TAL effector knockout strains were generated through a saturating screen of suicide vector integration events in the TAL effector coding region. Thirty-four independent insertions were screened by Western blot analysis and, in each case, at least one TAL effector was disrupted. We note that this method does not preclude the possibility of multiple TAL effectors of the same size being simultaneously knocked out. However, the five Xam668 TAL effectors were originally identified and sequenced from a cosmid library and the number of TAL effectors was estimated through restriction digest profiling. The data presented here combined with our previous work suggest that each differently sized TAL effector is unique.

Single knockouts for each of the five Xam668 TAL effectors were selected and virulence levels were assessed through observation of watersoaking symptom development and measurement of bacterial populations in planta over time. Disruption of TAL13 Xam668, TAL15 Xam668, and TAL22 Xam668 did not cause a visible alteration in the development of watersoaked lesions or measurable differences in bacterial growth (Fig. 1A and B). Disruption of either TAL14 Xam668 or TAL20 Xam668 resulted in a reduction in bacterial growth in both the leaf midvein (Fig. 1B and C), and the leaf apoplast (Supplementary Fig. S1A). In addition to its growth defect and in contrast to TAL14 Xam668, disruption of TAL2O Xam668 resulted in a reduction in watersoaking symptom development (Fig. 1A).

The Xam668 genome contains three differently sized plasmids in addition to chromosomal DNA, as visualized by agarose gel electrophoresis. Plasmid-cured strains assayed for TAL effector expression allowed us to determine that $T A L 20_{\text {Xam668 }}$ is the only TAL effector encoded on the smallest plasmid. The TAL2O Xam668 plasmid-cured strain (Xam668 $\triangle$ TAL20p) mimicked the symptom defect observed for Xam668 $\triangle$ TAL20, and reintroducing TAL20 Xam668 into the plasmid-cured strain [Xam668 $\Delta$ TAL20p(TAL20 $\left.{ }_{\text {Xam668 }}\right)$ fully complemented the symptom defect phenotype (Fig. 1A). Because the plasmidcured strain was marker free, we were able to generate a Xam$668 \Delta$ TAL14/DTAL20p double knockout. The double mutant showed a reduction in watersoaking when compared with wildtype Xam668 and less growth than Xam668 and either single mutant (Fig. 1A and B). These results suggest that TAL14 ${ }_{X a m 668}$ and TAL20 ${ }_{\mathrm{Xam} 668}$ make distinct contributions to $X$. axonopodis pv. manihotis virulence.

\section{TAL20 Xam668 increases watersoaking conferred by TAL20-deficient $X$. axonopodis pv. manihotis CIO151.}

$X$. axonopodis pv. manihotis CIO151 lacks a TAL20 Xam668 homolog and causes less watersoaking than Xam668 (Bart et al. 2012). To test whether TAL20 Xam668 would increase watersoaking of $X$. axonopodis pv. manihotis CIO151, native pro- 
moter-driven TAL2O Xam668 was transferred to strain CIO151 by conjugation. Watersoaking caused by CIO151(TAL20 Xam668 $_{\text {) }}$ was greater than that caused by CIO151 (Fig. 1D). However, CIO151(TAL20 ${ }_{\text {Xam668 }}$ ) did not grow to significantly higher levels in planta than CIO151.
RNA-Seq identifies cassava genes upregulated in response to $X$. axonopodis pv. manihotis infection.

To identify Xam668 TAL effector targets in cassava, we first used the program TALE-NT 2.0 to computationally predict possible targets based on the TAL effector DNA-binding code
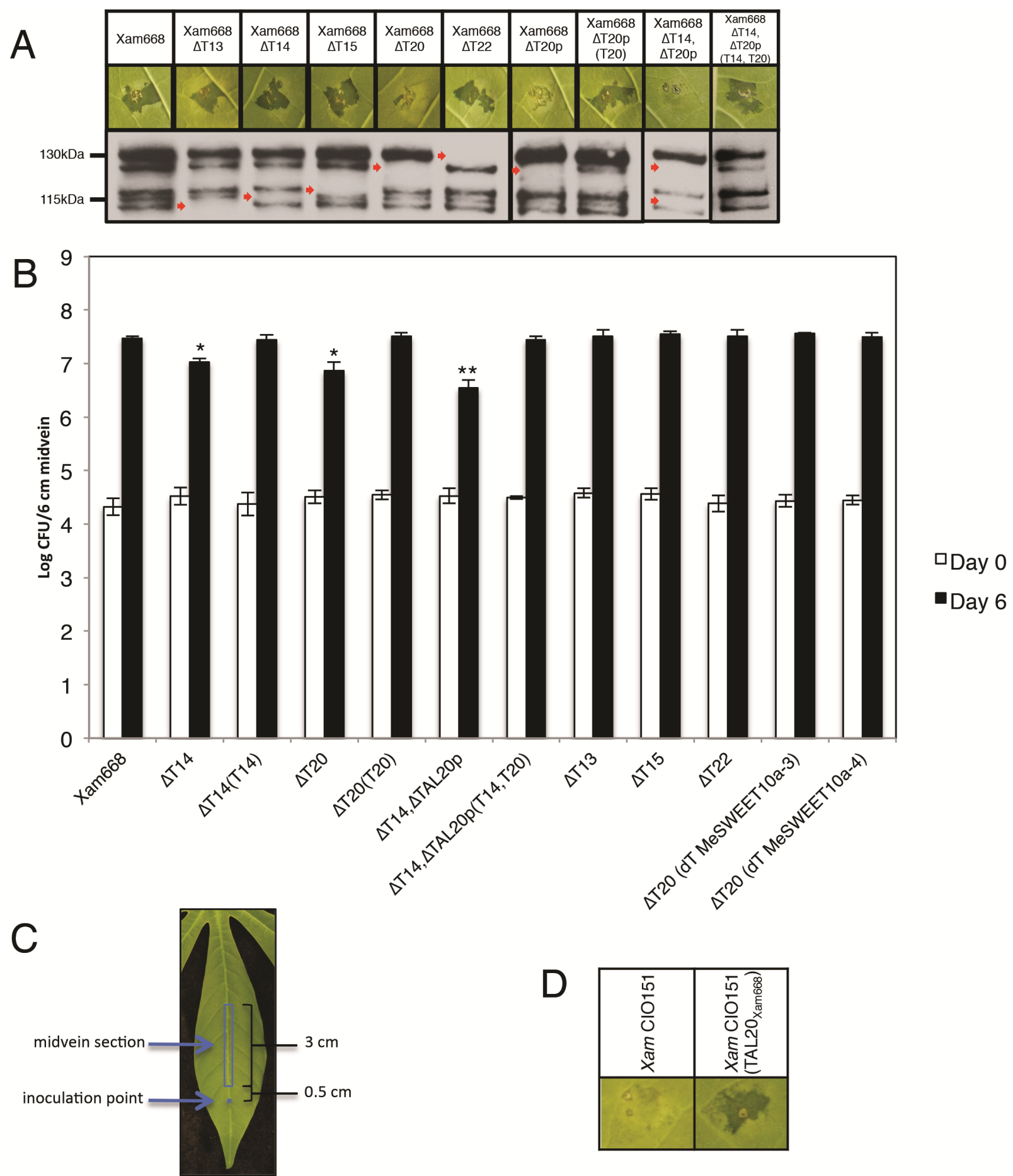

Fig. 1. Xanthomonas axonopodis pv. manihotis strain Xam668 contains five distinct transcription activator-like (TAL) effectors that contribute unequally to bacterial growth and symptom development. A, Knockouts (red arrows) were generated for each TAL effector and confirmed via Western blot analysis. TAL effector knockouts, TAL20 plasmid-loss, and double mutant lines were inoculated into cassava leaves (optical density at $600 \mathrm{~nm}\left[\mathrm{OD}_{600}\right]=0.01$ ) and symptom development was recorded after 5 days. B, Bacterial populations in leaf midveins were measured at day 0 and day 6 . Data are represented as mean CFU per $6 \mathrm{~cm}$ of leaf midvein $( \pm$ standard deviation). Asterisks: $*$ denotes significantly lower growth than Xam668, two-tailed $t$ test, $P$ value $<0.005$ and $* *$ de-

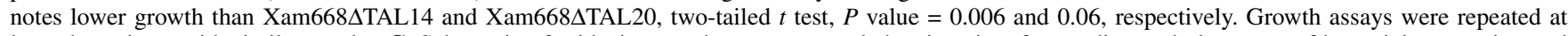
least three times with similar results. C, Schematic of midvein growth assay protocol showing site of wounding and placement of bacterial suspension and midvein section from which CFUs were counted. D, TAL20 Xam668 increases watersoaking symptoms of $X$. axonopodis pv. manihotis strain CIO151. Native promoter-driven TAL20 Xam668 was introduced into strain CIO151 by bacterial conjugation. Strains were inoculated into cassava leaves $\left(\mathrm{OD}_{600}=0.01\right)$ and symptom development was recorded after 6 days. $\mathrm{T}=\mathrm{TAL}, \mathrm{p}=$ plasmid. 
(Doyle et al. 2012). Even when the search area was narrowed to the 300-bp promoterome, there were still far too many targets to validate using molecular characterization alone (Fig. 2A). In addition, our experimental cassava cultivar of choice, 60444 , may contain promoter polymorphisms with respect to the reference genome AM560-2, hindering accurate TAL effector target prediction. Therefore, we undertook a transcriptomic approach to identify Xam668 TAL effector targets in cassava.

We designed an RNA-Seq experiment to identify the full repertoire of genes induced by Xam668 infection in cassava, as well as genes induced by TAL20 Xam668, chosen because of the virulence defects seen in the mutant strain. A cosmid clone from our previously published cosmid library (Bart et al. 2012) encoding TAL20 ${ }_{\text {Xam668 }}$ was conjugated into $X$. euvesicatoria 85-10. Notably, $X$. euvesicatoria 85-10 does not have any endogenous TAL effectors, does not elicit a hypersensitive reaction or disease symptoms when infiltrated into cassava leaves even at high inoculum, and is able to express TAL effectors encoded on cosmid clones or the pVSP61 plasmid (Supplementary Fig. S2). Our RNA-Seq experimental design encompassed three time points $(8,24$, and $50 \mathrm{~h}$ postinoculation [hpi]) and four experimental conditions (mock, Xam668, X. euvesicatoria, and $X$. euvesicatoria[TAL20 $\left.{ }_{\mathrm{Xam} 668}\right]$ ). Genes upregulated in Xam668 compared with mock infiltration were considered potential targets of the five Xam668 TAL effectors, whereas genes upregulated in $X$. euvesicatoria(TAL20 Xam668 $_{\text {) }}$ compared with $X$. euvesicatoria were considered to be

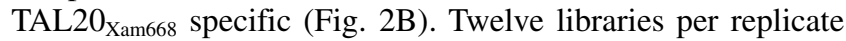
were indexed, pooled, and sequenced in a single lane on an Illumina HiSeq2000. In total, three biological replicates for each condition were compared. Illumina reads were aligned to the cassava reference genome AM560-2 using the TUXEDO suite of tools and default settings (Trapnell et al. 2012). Because our experiments were performed in cassava 60444, we allowed for two mismatches per read to accommodate possible single-nucleotide polymorphisms.
TAL20 ${ }_{\text {Xam668 }}$ directly targets MeSWEET10a.

We initially focused on identifying genes induced similarly in timing and intensity between mock versus Xam668 and $X$. euvesicatoria versus $X$. euvesicatoria(TAL20 Xam668). These analyses yielded a single putative target for TAL20 Xam668, cassava4.1_013474, henceforth referred to as MeSWEET10a, a member of the SWEET sugar transporter family of TAL effector-targeted susceptibility genes (Chen et al. 2012, 2010) (Fig. 3A; Supplementary Fig. S3). TAL effector dependence for activation was tested using $X$. euvesicatoria delivering individual Xam668 TAL effectors. Only TAL20 Xam668 was able to activate MeSWEET1Oa (Fig. 3B). In addition, MeSWEET10a was not activated by Xam668 $\triangle$ TAL20, suggesting that TAL20 Xam668 is solely responsible for induction of this gene (Fig. 4). Semiquantitative reverse-transcriptase polymerase chain reaction (RT-PCR) verified MeSWEET10a activation by X. axonopodis

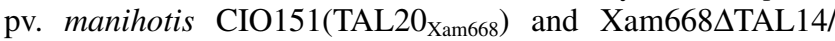
TAL20p(TAL14,TAL20), indicating that MeSWEET10a plays a role in the virulence and watersoaking phenotypes seen in these strains (Supplementary Fig. S4A and B).

To test whether MeSWEET1Oa activation is directly induced by TAL $20_{\text {Xam668 }}$, we pursued a transient approach in which the MeSWEET10a promoter was used to drive expression of the reporter gene luciferase in an Agrobacterium binary vector. The resulting construct was coexpressed with 35S-driven TAL20 Xam668 delivered via Agrobacterium tumefaciens in Nicotiana benthamiana leaf cells. Luciferase activity was measured $24 \mathrm{~h}$ after inoculation. Agrobacterium tumefaciens delivering $T A L 20_{\text {Xam668 }}$ specifically induced expression of the MeSWEET10a promoter (Fig. 3C). Previous research has demonstrated that an $X$. oryzae pv. oryzae TAL effector-targeted EBE placed in the $B s 3$ promoter from pepper (normally targeted by $X$. euvesicatoria TAL effector AvrBs3) retains its function (Römer et al. 2009); therefore, we tested whether this was true for the predicted TAL20 Хam668 targeted EBE from the MeSWEET10a promoter (Supplementary Table S2). Although
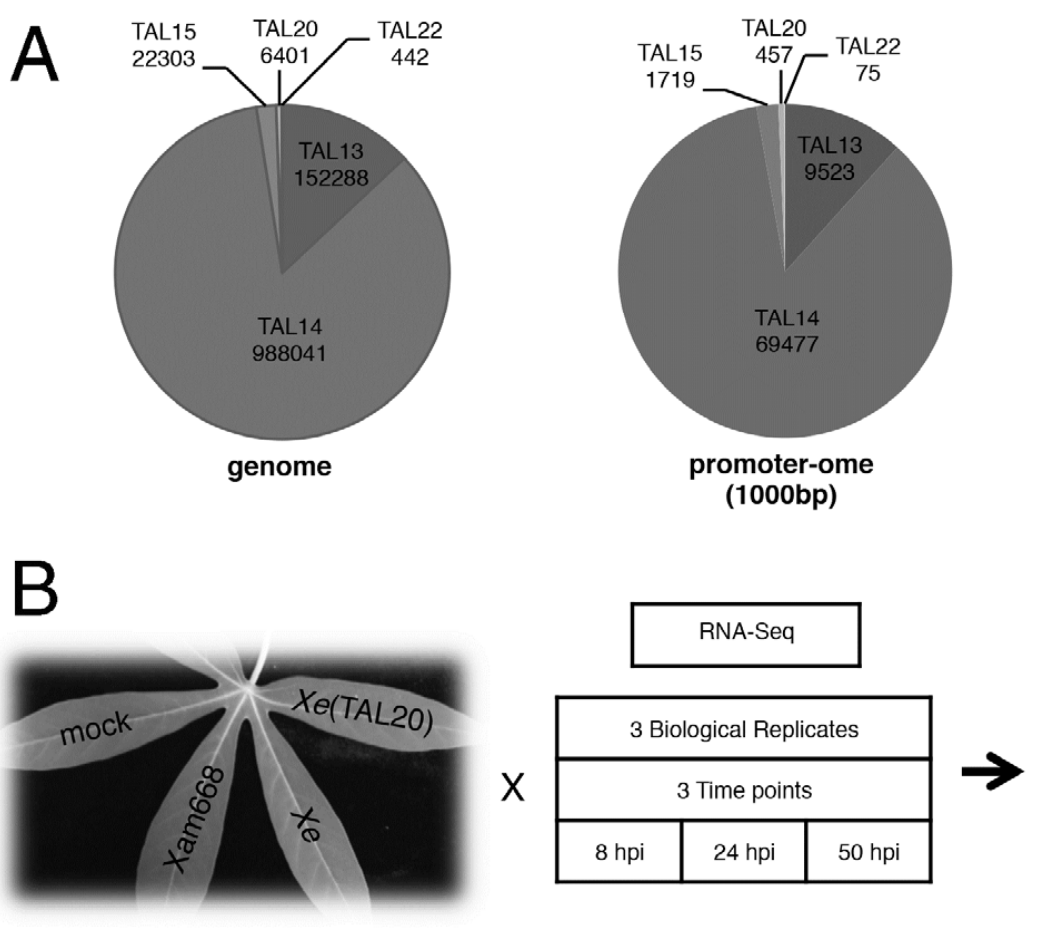

(1000bp)
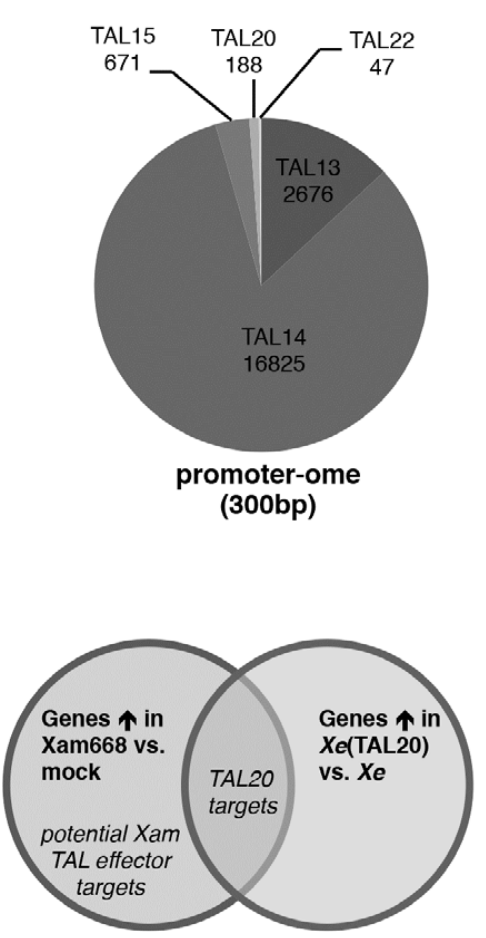

Fig. 2. Transcription activator-like (TAL) effector target prediction and strategy for experimental identification. A, Pie charts show the number of computationally predicted targets for each Xam668 TAL effector within the full cassava genome (left), 1,000 bp from an annotated start codon (middle), and 300 bp from an annotated start codon (right). Predictions were made using TALE-NT 2.0 (Doyle et al. 2012) scanning the genome of cassava AM560-2. B, Cartoon of experimental strategy for identifying TAL effector targets; hpi = hours postinoculation. 
TAL20 ${ }_{\text {Xam668 }}$ did not induce expression of the wild-type Bs3 promoter, when the predicted TAL20 Xam668 $\mathrm{EBE}$ was inserted into the $B s 3$ promoter, activation was observed (Fig. 3C). We note that the tested promoters do not display identical background levels and speculate that this is a result of their differential interaction with endogenous transcription activators or repressors.

Electromobility shift assays confirmed direct interaction between TAL20 ${ }_{\text {Xam668 }}$ and an oligonucleotide encompassing the predicted TAL20 Xam668 EBE from the MeSWEET10a promoter (Supplementary Fig. S5A). Additionally, MeSWEET10a gene activation was seen in the presence of $50 \mu \mathrm{M}$ cycloheximide (CHX), an inhibitor of eukaryotic protein synthesis. Taken together, our data show that the MeSWEET1Oa promoter is directly bound and activated at the predicted EBE by TAL20 Xam668.
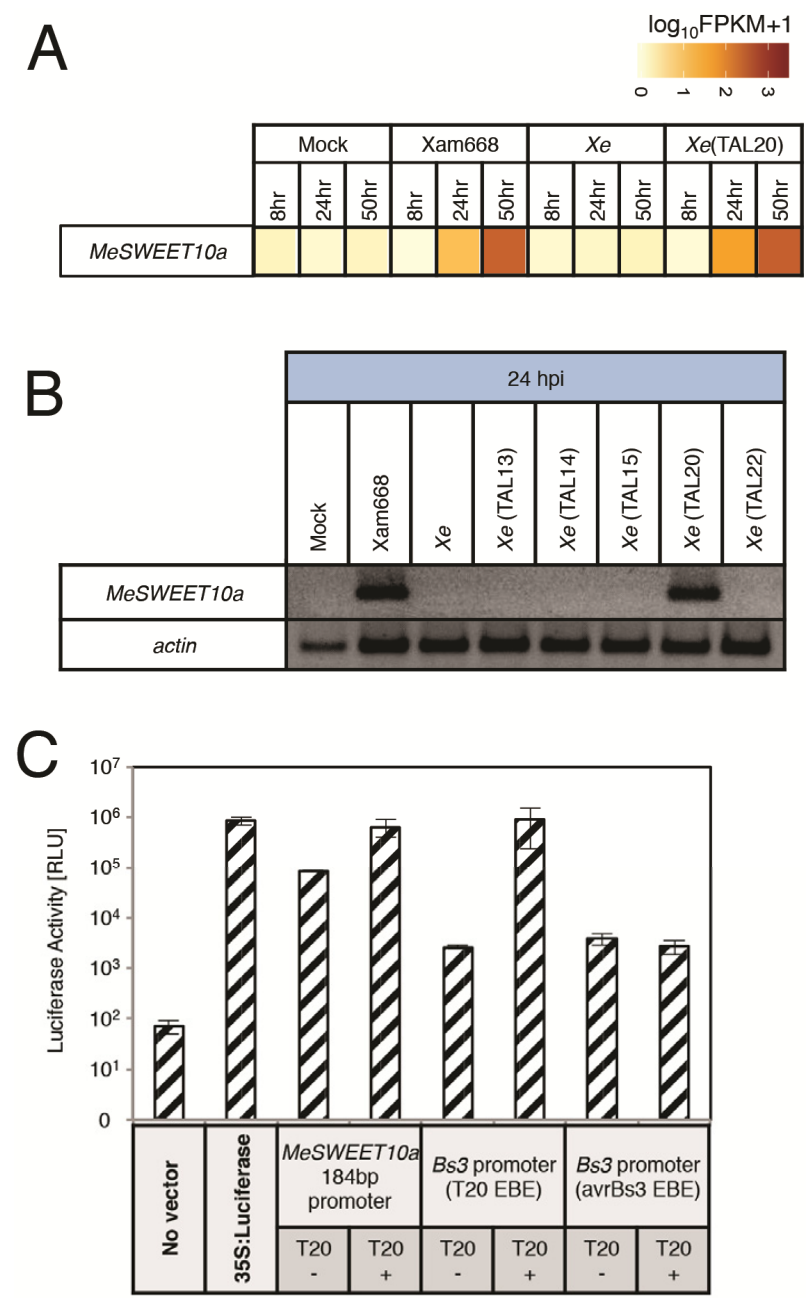

Fig. 3. TAL20 ${ }_{\text {Xam668 }}$ directly activates expression of MeSWEET1Oa. A, RNA sequencing (RNA-Seq) data showing expression of MeSWEET1Oa in mock- (wounding), Xam668- (five distinct transcription activator-like [TAL] effectors), Xanthomonas euvesicatoria 85-10- (no TAL effectors), and X. euvesicatoria 85-10 (TAL20 Xam668)-inoculated cassava leaves 8, 24, and $50 \mathrm{~h}$ postinoculation (hpi). Heat map of $\log _{10}$ FPKM values represents the mean of three biological replicates. B, Semiquantitative reverse-transcriptase polymerase chain reaction of MeSWEET10a expression $24 \mathrm{hpi}$ in leaf tissue inoculated at an optical density at $600 \mathrm{~nm}$ of 0.5 with $X$. euvesicatoria 85-10 delivering each of the five Xam668 TAL effectors. Experiment was repeated three times with similar results. C, Agrobacterium tumefaciens was used to deliver promoter-luciferase fusion constructs and 35S-driven TAL20 Xam668 into Nicotiana benthamiana cells. Luciferase activity was quantified 24 hpi. Data are displayed as mean technical replicates $( \pm$ standard deviation). Experiments were repeated three times with similar results; $\mathrm{EBE}=$ effector-binding element. $\mathrm{T}=\mathrm{TAL}$.
dTALE restore Xam668 $\triangle$ TAL20 virulence defects.

To test the role of MeSWEET1Oa as a host susceptibility gene, dTALE targeting distinct places within the MeSWEET10a promoter ( $\mathrm{dT}_{\text {MeSWEET10a-3 }}$ and $\left.\mathrm{dT}_{\text {MeSWEET10a-4 }}\right)$ were assembled with code-optimized RVD sequences (Supplementary Fig. S6) (Boch et al. 2009; Moscou and Bogdanove 2009). dT MesweET10a-3 and $\mathrm{dT}_{\text {MesweET10a-4 }}$ were conjugated into Xam668 $\mathrm{TAL} 20$ and the resulting strains were assessed for restoration of virulence phenotypes. Both $\mathrm{dT}_{\text {MeSwEET10a-3 }}$ and $\mathrm{dT}_{\text {MeSwEET10a-4 }}$ were able to activate expression of MeSWEET1Oa, and both complemented symptom development (Fig. 4) and bacterial growth (Fig. 1B) in Xam668 TTAL20. Complementation of the Xam668 $\triangle$ TAL20 mutant phenotype by dTALE that activate MeSWEET10a shows that TAL20 ${ }_{\text {Xam668 }}$ contributes to $X$. axonopodis pv. manihotis virulence through the activation of MeSWEET10a, and that MeSWEET10a carries out a function in the plant that, when coopted by $X$. axonopodis pv. manihotis, promotes disease susceptibility.

\section{MeSWEET10a is a sugar transporter.}

Phylogenetic analysis indicates that MeSWEET10a belongs to clade III of the SWEET sugar transporter family and is most closely related to the Arabidopsis sucrose transporter AtSWEET10 (Chen et al. 2012) (Fig. 5A). Several recent studies indicate that pathogens induce sucrose export from cells into the apoplasm to be used as a carbon source (Chen 2014; Chen et al. 2010, 2012; Sonnewald 2011). If, indeed, the $X$. axonopodis pv. manihotis virulence strategy follows this model, we hypothesized that disrupting the ability of $X$. axonopodis pv. manihotis to import sucrose should result in a phenotype similar to that observed from blocking induction of MeSWEET10a (Xam668DTAL20). SuxC was identified as part of an operon from $X$. campestris pv. campestris that is specific for sucrose import and essential to $X$. campestris pv. campestris fitness (Blanvillain et al. 2007). To test the above hypothesis, we generated a deletion mutant in the orthologous SuxC gene of $X$. axonopodis pv. manihotis and confirmed that Xam668 $\Delta$ suxC was unable to grow when sucrose was provided as the only carbon source (Fig. 5B). Notably, in minimal media, Xam668 $\Delta$ suxC could still utilize glucose. We inoculated this mutant into cassava leaves and observed no significant reduction in growth (Fig. 5C). Although the watersoaking caused by Xam668DTAL20 was reduced, watersoaking by Xam668 $\Delta$ suxC was similar to wild-type Xam668 (Fig. 5D). These results indicate that the induction of MeSWEET10a

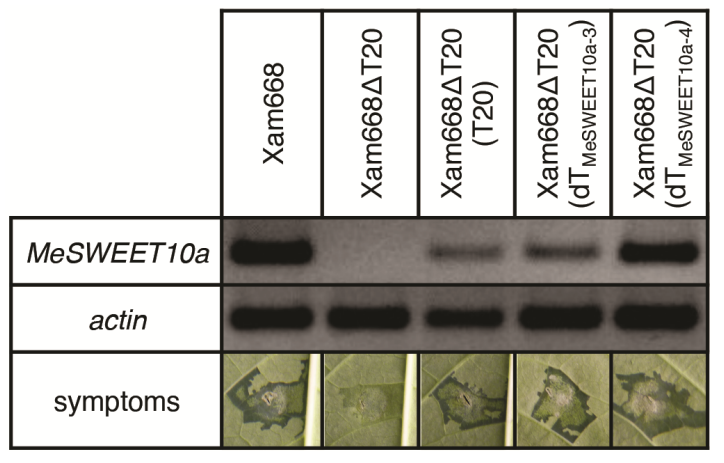

Fig. 4. MeSWEET1Oa-targeted designer transcription activator-like effectors (dTALE) restore virulence defects of Xam668 $\triangle$ TAL20. dTALE designed to target locations within the MeSWEET1Oa promoter were conjugated into Xam668DTAL20. Semiquantitative reverse-transcriptase polymerase chain reaction was used to confirm MeSWEET1Oa transcript induction $24 \mathrm{~h}$ postinoculation. Watersoaking symptom development was assessed at 5 days postinoculation for Xam668 4 TAL20 and dTALE-complemented strains inoculated at an optical density at $600 \mathrm{~nm}$ of 0.1 . Experiments were repeated three times with similar results. $\mathrm{T}=\mathrm{TAL}$. 

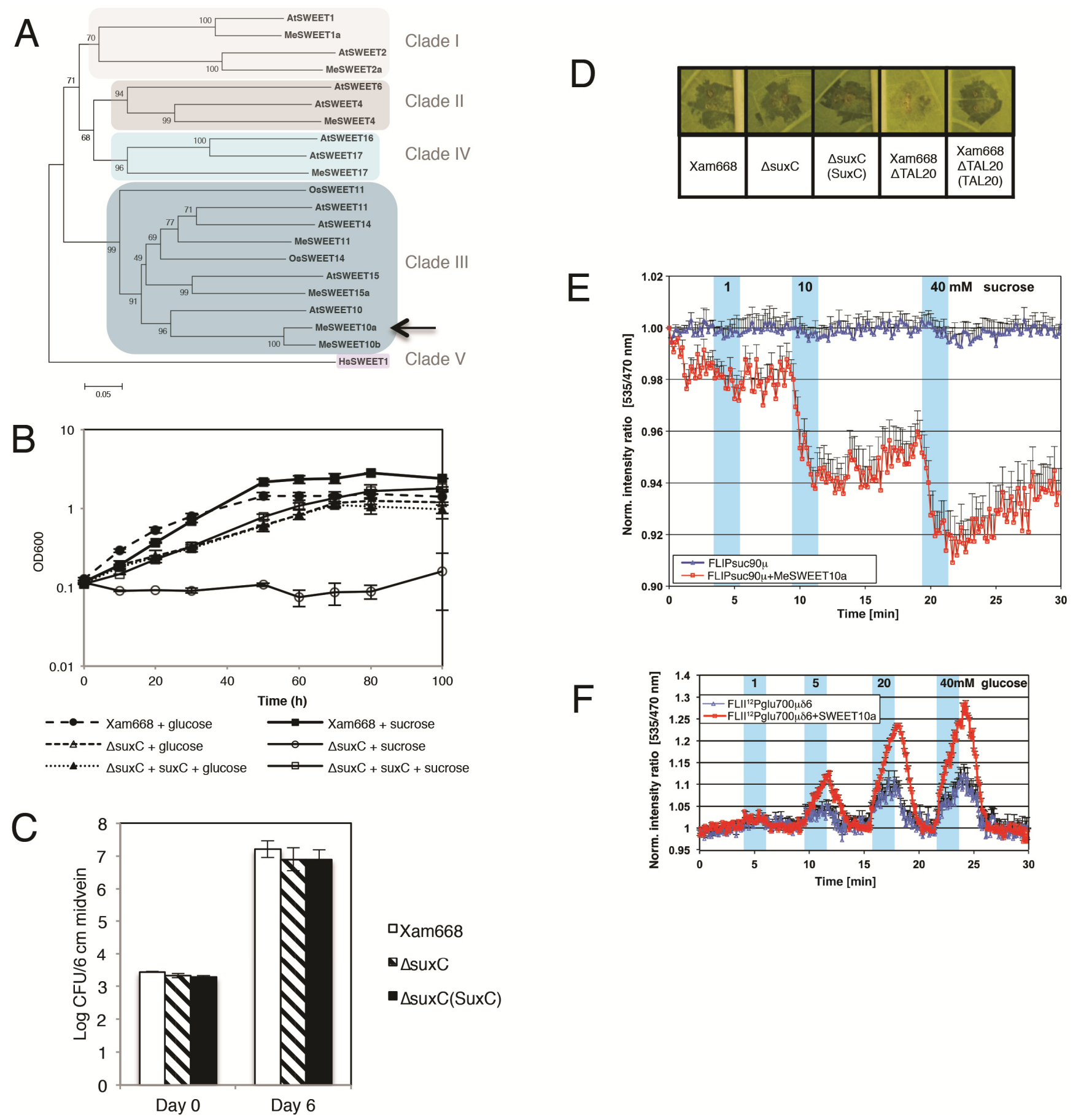

Fig. 5. MeSWEET10a is a member of the clade III family of sugar transporters. A, SWEET proteins from Arabidopsis thaliana (At), Oryza sativa (Os), and Homo sapiens (Hs) were chosen to represent clades of the SWEET superfamily (Chen et al. 2010). The phylogenetic tree was made using the neighbor-joining method in MEGA version 5.2.2 (Tamura et al. 2011). Bootstrap values (percentage of 1,000) are displayed. B, A full gene knockout was constructed for

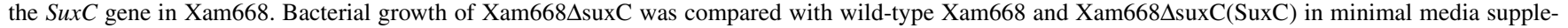

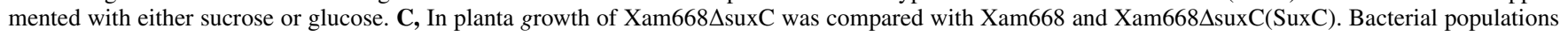
in leaf midveins were measured at day 0 and day 6 . Data are represented as mean CFU per 6-cm leaf midvein ( \pm standard deviation). Growth assays were repeated at least three times with similar results. D, Symptom development was compared for Xam668, Xam668 suxC, Xam668 TTAL20, and complemented mutant lines. Pictures representative of seven independent replicates were taken 5 days after inoculation (optical density at $600 \mathrm{~nm}=0.1$ ). E, MeSWEET10a mediates sucrose transport activity as detected by coexpression with the cytosolic Förster resonance energy transfer (FRET) sucrose sensor FLIPsuc90 $\mu \Delta 1$ a in HEK293T cells (Chen et al. 2012). Individual cells were analyzed by quantitative ratio imaging of eCFP and Aphrodite emission (acquisition interval of 10 s). HEK293T cells were perfused with culture medium, followed by square pulses of increasing sucrose concentrations. Blue line indicates cells expressing sensor alone; red line indicates cells coexpressing sensor and MeSWEET10a; accumulation of sucrose is indicated by a negative FRET ratio change (mean + standard error [s.e.]; $n>19)$. Experiments were repeated with comparable results at least four times. F, MeSWEET10a mediates glucose transport activity as detected by coexpression with the cytosolic FRET glucose sensor FLII ${ }^{12}$ Pglu700 $\mu \vartheta 6$ in HEK293T cells (Chen et al. 2010). Individual cells were analyzed by quantitative ratio imaging of eCFP and Citrine emission (acquisition interval of $5 \mathrm{~s}$ ). HEK293T cells were perfused with culture medium, followed by square pulses of increasing glucose concentrations. Blue line indicates cells expressing sensor alone; red line indicates cells coexpressing sensor and MeSWEET10a; accumulation of glucose is indicated by a positive FRET ratio change (mean +s.e.; $n>15$ ). Experiments were repeated with comparable results at least four times. 
contributes to bacterial growth and watersoaking independently of the bacteria's ability to directly utilize sucrose in the apoplasm. Although clade III transporters typically function as sucrose transporters, some members of this clade have been found to transport both glucose and sucrose. To test the sugar transport capabilities of MeSWEET10a, the protein was expressed in mammalian cells together with sucrose and glucose Förster resonance energy transfer (FRET) sensors (Chen et al. 2010). Sucrose and glucose-induced FRET responses indicate that MeSWEET10a can transport both sucrose and glucose (Fig. 5E and F).

\section{Correlating induced genes with specific TAL effectors.}

To identify targets of TAL13 Xam668, TAL14 Xam668, TAL15 Xam668, and TAL22 2 am668, we examined our RNA-Seq data for genes that were highly induced by Xam668 as compared with mock in at least two of the three time points ( $8 \mathrm{hpi}$ and $24 \mathrm{hpi}, 24 \mathrm{hpi}$ and $50 \mathrm{hpi}$, or in all three time points). We cross-referenced the set of induced genes with the list of putative EBE predicted by TALE-NT 2.0 and found that many induced genes contained EBE with what are considered good scores (within a threefold cutoff of the best possible score for the given TAL effector) within their promoters (Doyle et al. 2012). A heat map for a manually selected subset of the most highly induced candidate TAL effector targets is presented (Fig. 6, left).

We assigned TAL effector specificity to the subset of putative target genes by carrying out semiquantitative RT-PCR on cassava leaves inoculated with $X$. euvesicatoria strains delivering individual Xam668 TAL effectors. Of the 17 genes tested, we found that 1 was upregulated by TAL $13_{\text {Xam668, nine }}$ by TAL14 ${ }_{\text {Xam668 }}$, two by TAL15 Xam668, and four by TAL22 Xam668. No additional genes were found to be upregulated by TAL20 Xam668 (Fig. 6, right). To test whether the TAL effectors were directly activating these target genes, we carried out inoculations in the presence of $50 \mu \mathrm{M} \mathrm{CHX}$. All genes tested were activated in a TAL effector-dependent manner in both the presence and absence of $\mathrm{CHX}$, indicating that activation is direct (Supplementary Fig. S7). A slight decrease in expression was observed for 024404 and 026646 , suggesting that these two genes may be indirect targets. However, the expression was not reduced to background levels; therefore, the decrease may be due to biological variation between samples. Most of the validated targets have one or more EBE specific to the TAL effectors by which they are activated in their promoters. The 020499 promoter contains multiple TAL14 ${ }_{\mathrm{Xam} 668}$ EBE when the stringency for EBE score is relaxed to be within 3.5-fold of the best possible score. Similarly, the 029452 promoter contains two TAL13 Xam668 EBE when the score stringency is reduced to be within fourfold of the best possible score. EBE for TAL22 Xam668 were identified in the promoters of 018388 and 020556 by the program TALVEZ but not by TALE-NT, presumably because of differences in the programs' predictive RVD-nucleotide association matrices (Pérez-Quintero et al. 2013).

Finally, because our Western blot did not convincingly show TAL14 ${ }_{\text {Xam668 }}$ complementation of our TAL14 Xam668 $/$ TAL20 Xam668 double mutant (Xam668 4 TAL14/TAL20p(TAL14,TAL20) (Fig. 1A), we used semiquantitative RT-PCR to detect activation of the TAL14 target 007568 , confirming TAL14 complementation.

\begin{tabular}{|c|c|c|c|c|c|c|c|c|c|c|c|c|c|c|c|}
\hline & & & & & & & & & & & & & & & \\
\hline & & & & RNA & & & & & & & RT-F & PCR & & & \\
\hline & & & Mock & & & $\operatorname{am} 66$ & & & & & 24 & hpi & & & \\
\hline ID $^{1}$ & Functional Annotation ${ }^{2}$ & $\stackrel{\grave{L}}{\infty}$ & $\frac{\grave{I}}{\mathrm{~d}}$ & 홍 & $\stackrel{\grave{L}}{\infty}$ & 亳 & 홈 & $\begin{array}{l}\text { ॐ̆ } \\
\text { ¿ }\end{array}$ & 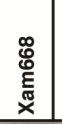 & $\ddot{x}$ & 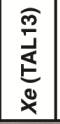 & 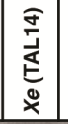 & 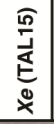 & 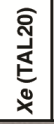 & 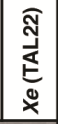 \\
\hline $034150^{* \star}$ & D-mannose binding lectin protein & & & & & & & & $\infty$ & $=$ & - & 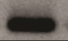 & - & - & \\
\hline 031361 & no functional annotation & & & & & & & & - & & & - & & & \\
\hline $030094^{\star \star \star}$ & Homeobox domain, transcription factor activity & & & & & & & & - & & & - & & & \\
\hline 029949 & Dof-type zinc finger domain, regulation of transcription & & & & & & & & - & & & & & & - \\
\hline $029452^{*}$ & Dynein light chain type 1 family protein & & & & & & & & - & 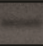 & - & $1=$ & - & - & $+n$ \\
\hline $027342^{\star \star}$ & Integrase-type DNA-binding superfamily protein & & & & & & & & - & $\div$ & $=$ & $=1$ & $\Leftrightarrow$ & $=$ & $=$ \\
\hline 026646 & Eukaryotic aspartyl protease family protein & & & & & & & & - & & & - & & & \\
\hline 026121 & no functional annotation & & & & & & & & - & & & $\rightarrow$ & & & \\
\hline 024404 & Serine carboxypeptidase-like protein & & & & & & & & - & & & - & & & $=$ \\
\hline $023036^{* *}$ & D-mannose binding lectin protein & & & & & & & & 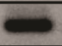 & $=$ & - & $\Leftrightarrow$ & $=$ & - & 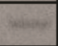 \\
\hline 020556 & Low-molecular-weight cysteine-rich 69 & & & & & & & & 2 & & & $=$ & & & $=$ \\
\hline 020499 & Metallothionein & & & & & & & & - & & & - & & & \\
\hline 019269 & CLAVATA3/ESR-RELATED 41 & & & & & & & & $=$ & & & & & & - \\
\hline 018388 & $2 \mathrm{Fe}-2 \mathrm{~S}$ iron-sulfur cluster binding domain & & & & & & & & - & & & & & & - \\
\hline 017922 & Brassinosteroid-responsive RING-H2 & & & & & & & & - & - & - & - & - & & \\
\hline 007568 & Pectate lyase-like superfamily protein & & & & & & & & - & & & - & & & \\
\hline 009807 & actin & & & & & & & - & $\infty$ & - & $=$ & $\infty$ & 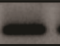 & & - \\
\hline
\end{tabular}

1PhytozomelD (cassava4.1 \#\#\#\#\#)

${ }^{2}$ Functional annotation from $2 / 26 / 13$

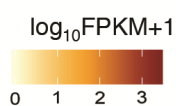

Fig. 6. Specific gene upregulation during Xanthomonas axonopodis pv. manihotis infection can be attributed to individual transcription activator-like (TAL) effectors. Subset of RNA sequencing (RNA-Seq) data showing genes induced by Xam668 (five distinct TAL effectors) but not in mock (wounding)-inoculated cassava leaves shows potential TAL effector targets. Heat map of $\log _{10}$ FPKM values represents the mean of three biological replicates. Semiquantitative reverse-transcriptase polymerase chain reaction $(\mathrm{PCR})$ of leaf tissue inoculated (optical density at $600 \mathrm{~nm}=0.5$ ) with Xanthomonas euvesicatoria 85-10 delivering each of the five Xam668 TAL effectors shows TAL effector-dependent gene activation. Experiment was repeated three times with consistent results. In all, 25 cycles of PCR were carried out, unless otherwise indicated $(*=28$ cycles, $* *=23$ cycles, and $* * *=30$ cycles $)$. 


\section{Presence of TAL20 in diverse}

$X$. axonopodis pv. manihotis strains correlates

with MeSWEET10a induction and watersoaking.

To determine the level of conservation among $X$. axonopodis pv. manihotis isolates in the ability to induce MeSWEET1Oa during infection, we selected a variety of naturally occurring field isolates of $X$. axonopodis pv. manihotis (Bart et al. 2012) and tested MeSWEET1Oa induction by semiquantitative RTPCR. In addition, we assessed the number and approximate sizes of TAL effectors in these strains by Western blot (Fig. 7A). We found that MeSWEET1Oa induction is conserved in nine of 11 strains and correlates with relatively higher levels of watersoaking (Fig. 7B). All strains capable of inducing MeSWEET1Oa expressed a TAL effector similar in size to TAL20 ${ }_{\mathrm{Xam} 668}$.

\section{DISCUSSION}

TAL effectors constitute a major class of virulence factors used by xanthomonads during infection of their host plants. In this work, an RNA-Seq approach was used to study transcriptional changes induced during TAL effector introduction into plant cells. We chose as our pathosystem the important food crop cassava and its major bacterial pathogen $X$. axonopodis pv. manihotis. A differential contribution to virulence was found for the five TAL effectors of strain Xam668, with TAL20 Xam668 influencing bacterial growth and symptom formation; TAL14 Xam668 contributing to growth; and TAL13 ${ }_{\text {Xam668 }}$, TAL15 $5_{\text {Xam668 }}$, and TAL22 $2_{\text {Xam668 }}$ showing no detectable effect on virulence. This variation is consistent with what is reported in the literature for other TAL effector family members and makes sense, given that TAL effectors are defined as transcriptional activators but their specific function in the host is dependent on their RVD sequence and the interaction of their RVD specificity with the host genotype. Like TAL20 ${ }_{\text {Xam668 }}$ TAL effectors avrXa7 and PthXo1 of $X$. oryzae pv. oryzae, PthA of $X$. campestris pv. campestris, and TALE1 $1_{\text {Xam }}$ of $X$. axonopodis pv. manihotis CFBP1851 have been reported to contribute to both growth and symptom formation (Bai et al. 2000; Castiblanco et al. 2013; Swarup et al. 1991; Yang and White 2004). The phenotype of Xam668ATAL14 shows that an influence on bacterial growth can be uncoupled from symptom development. Similarly, Tal2g of $X$. oryzae pv. oryzicola contributes to lesion length and watersoaking in rice but not to bacterial growth (Cernadas et al. 2014), and AvrB6 from X. campestris pv. malvacearum contributes to watersoaking and necrosis but not to growth in cotton (Gossypium hirsutum) (Yang et al. 1994). TAL effectors that have no effect when mutated have also been reported numerous times in the literature (Bai et al. 2000; Cernadas et al. 2014; Yang et al. 1996).

Our RNA-Seq experimental design allowed us to identify transcriptional changes induced by all five TAL effectors encoded by the Xam668 genome (within the mock versus Xam668 data set) and also to distinguish the transcriptional changes caused specifically by the TAL effector TAL20 Xam668 $(X$. euvesicatoria versus $X$. euvesicatoria delivering TAL20 ${ }_{\text {Xam668 }}$ ). Despite the fact that 457 annotated cassava promoters contain potential
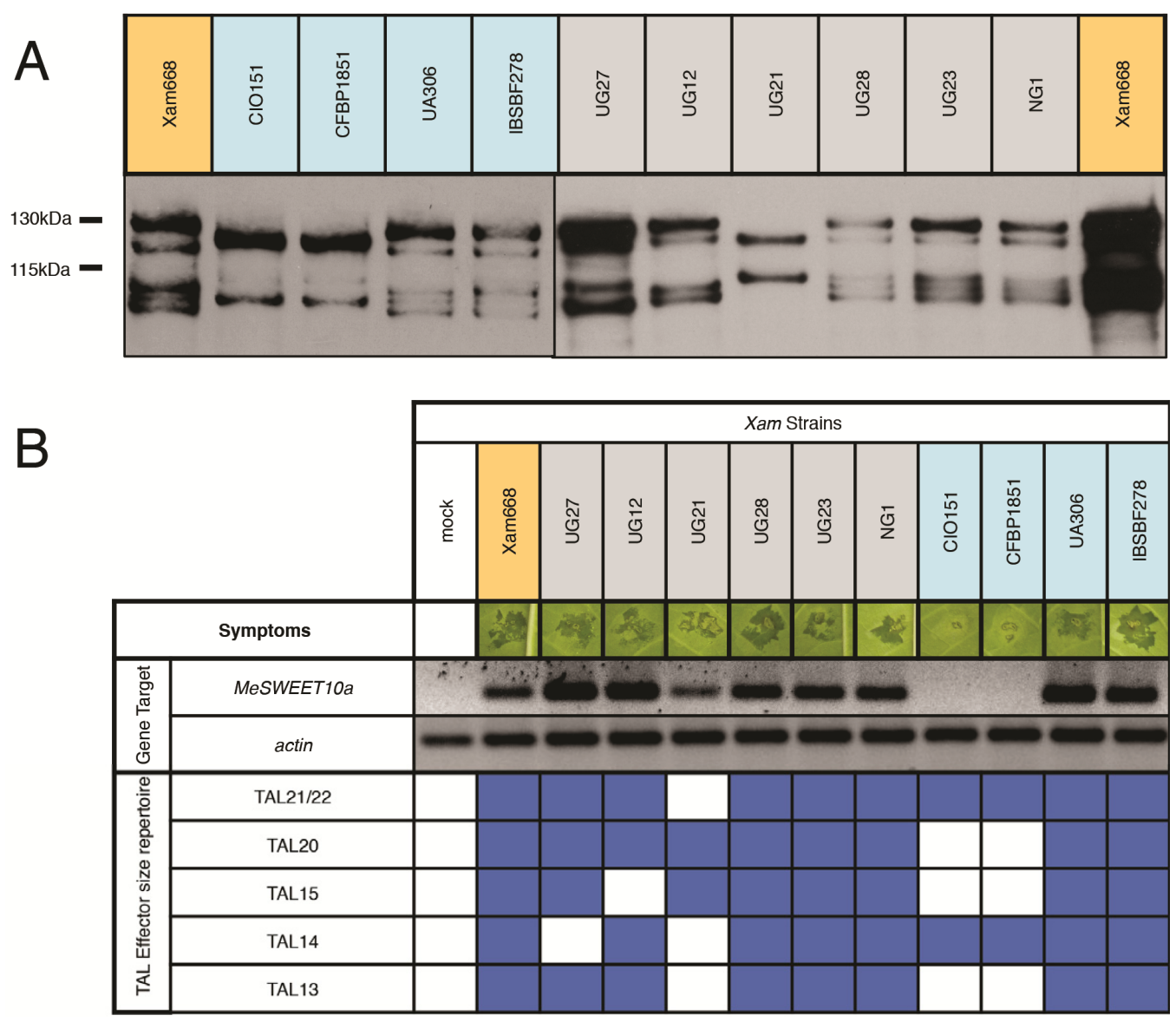

Fig. 7. Multiple Xanthomonas axonopodis pv. manihotis strains from Asia, Africa, and South America (highlighted in orange, gray, and light blue, respectively) activate MeSWEET10a. A, Transcription activator-like (TAL) effector sizes for each strain were estimated based on Western blot. B, Semiquantitative reverse-transcriptase polymerase chain reaction shows activation of MeSWEET1Oa by various strains. Results of the Western blot are displayed figuratively, with blue and white squares indicating the presence or absence of TAL effectors with the specified number of repeat variable diresidues, respectively. Symptom development for each strain is shown. Leaves were imaged 7 days postinoculation (optical density at $600 \mathrm{~nm}=0.01$ ). 
TAL20 Xam668 EBE, only a single transcript, MeSWEET10a, was induced to similar levels by both Xam668 and X. euvesicatoria(TAL20 ${ }_{\text {Xam668 }}$ ). Notably, there are predicted EBE for TAL13 Xam668 and TAL14 ${ }_{\text {Xam668 }}$ in the MeSWEET10a promoter in addition to the TAL20 Xam668 EBE, yet activation is dependent only on TAL20 Xam668. Mechanisms of TAL effector target specificity not mediated by RVD-base pair interaction are still being elucidated. It has been shown that TAL effector-dependent activation is limited by epigenetic modifications; therefore, chromatin state is a likely factor contributing to specificity (Bultmann et al. 2012). Recently, it was shown that adding constraints such as a lower relative EBE score (ratio of actual score to the score of a hypothetical perfect match) requirement and increased stringency for distance from the transcriptional start site can reduce the incidence of falsely predicted targets (Cernadas et al. 2014). Other factors contributing to specificity may include precision gained by members of the transcriptional complex or currently undiscovered specificity constraints built into TAL effectors themselves.

To identify targets of TAL13 $3_{\text {Xam668, }}$ TAL14 ${ }_{\text {Xam668 }}$, TAL15 Xam668, and TAL22 $2_{\text {Xam668, }}$, we turned to our mock versus Xam668 RNASeq data set. Seventeen likely targets were selected based on expression profile and were subsequently shown to be activated by TAL effectors. Some targets lend themselves to hypotheses of function: TAL14 $4_{\text {Xam668 }}$-targeted 007568 , a pectate lyase, may aid bacterial colonization of the leaf and vascular tissues. Pectate lyases have been reported to promote disease in plants: bacteria in the genus Erwinia secrete pectate lyase enzymes via the type II secretion pathway to break down plant cell walls and cause symptoms of soft rot (Brencic and Winans 2005); PMR6, an Arabidopsis pectate lyase-like gene, is required for susceptibility to powdery mildew infection (Vogel et al. 2002); and cell wall pectic structures were previously shown to be highly altered during $X$. axonopodis pv. manihotis infection of cassava (Boher et al. 1995). Interestingly, X. euvesicatoria AvrBs3 was found to induce pepper pectate lyase upa8, and the $X$. campestris pv. campestris PthA-targeted CsLOBI transcription factor was associated with expression of pectate lyase Cit.39387 (Hu et al. 2014; Marois et al. 2002). A metallothionein, 020499, may be induced in order to sequester toxic metals away from $X$. axonopodis pv. manihotis (Leszczyszyn et al. 2013). Genes 030094, 029949, and 027342 are annotated as transcription factors, which is consistent with reports of TAL effectors affecting multiple changes in the host transcriptome by directly activating a host transcription factor $(\mathrm{Hu}$ et al. 2014; Kay et al. 2007; Li et al. 2014). Although TAL20 Хam668 has a single host target, TAL14 ${ }_{\text {Xam668 }}$ has many which may contribute collectively to virulence. The absence of a mutant phenotype for TAL13 $3_{\text {Xam668 }}$, TAL15 Xam668, and TAL22 Xam668 despite having bona fide host targets may be attributed to effector functional redundancy or to the challenge of measuring bacterial fitness in a laboratory setting. Laboratory experiments are hindered by an inability to include all potential pathogen life stages or environmental stresses, measure infection over long periods of time, or include large numbers of replicates. Additionally, TAL13 ${ }_{\text {Xam668 }}$, TAL15 ${ }_{\text {Xam668 }}$, and TAL22 Xam668 may have susceptibility targets in host cultivars other than our experimental 60444.

MeSWEET1Oa is a sugar transporter related to the susceptibility genes OSSWEET11 and OSSWEET14 in rice. OSSWEET11 and $O s S W E E T 14$ are activated by multiple TAL effectors from $X$. oryzae pv. oryzae, and their activation promotes disease progression (Antony et al. 2010; Streubel et al. 2013; Yang et al. 2006; Yu et al. 2011). MeSWEET1Oa resides in clade III of the SWEET transporters along with OsSWEET11 and OsSWEET14. Interestingly, another clade III SWEET, cassava4.1_014124, was upregulated in our mock versus Xam668 data set but its TAL effector dependence was not tested in this study. Clade III SWEET transporters appear to be particularly relevant for disease promotion, because a clade I SWEET from citrus, CsSWEET1, was identified as an X. campestris pv. campestris TAL effector target but no role in susceptibility was found ( $\mathrm{Hu}$ et al. 2014). Clade III SWEET transporters in rice not yet shown to be TAL effector targets increased virulence of $X$. oryzae pv. oryzae when specifically activated by dTALE, while SWEET transporters from other clades did not (Streubel et al. 2013). The cassava genome encodes 23 putative SWEET members, 13 in clade III, based on annotations available on Phytozome (Goodstein et al. 2012; Prochnik et al. 2012). The reason for the specific role of MeSWEETIOa in susceptibility is unknown.

SWEET transporters facilitate glucose and sucrose efflux from mesophyll cells into the apoplasm, and are likely involved in phloem loading (Chen 2014). Because clade III SWEET transporters were found to preferentially transport sucrose, it was hypothesized that pathogens induce expression of SWEET genes to increase sucrose export from cells into the apoplasm to be used as a pathogen carbon source (Chen et al. 2010, 2012). We explored the proposed link between SWEET transporter induction and pathogen sucrose utilization by comparing disease phenotypes of Xam668 $\Delta$ TAL20, which does not activate MeSWEET10a, and Xam668AsuxC, which cannot import sucrose. Xam668 $\Delta$ suxC did not show a significant defect in growth in planta, which is likely explained by its ability to utilize carbon sources in the apoplasm other than sucrose. Glucose exported by MeSWEET10a may be used directly, while exported sucrose may be broken down into hexose sugars by a host cell wall invertase enzyme (Kocal et al. 2008; Sturm 1999). This hypothesis is supported by our RNA-Seq data that show that one cassava gene annotated as an invertase is expressed and another is specifically induced during Xam668 infection (1.9-fold induction at $50 \mathrm{hpi}$ ). Both contain a signal peptide predicted by SignalP 4.1 (Petersen et al. 2011). In contrast to the phenotype of Xam668DTAL20, watersoaking was largely unaffected by the mutation of $S u x C$. Taken together, our results show that MeSWEET1Oa's contribution to virulence can be independent of $X$. axonopodis pv. manihotis's ability to directly utilize apoplastic sucrose.

Although both the absence of TAL14 ${ }_{\text {Xam668 }}$ and TAL20 Xam668 lead to a reduction in bacterial growth, only when MeSWEET10a is not activated (Xam668DTAL20) do we observe a significant reduction in watersoaking. In addition, TAL20 ${ }_{\text {Xam668 }}$ increases watersoaking by TAL20-deficient strain $X$. axonopodis pv. manihotis CIO151 but does not cause a significant increase in growth. The fact that growth can be uncoupled from watersoaking indicates that the role of symptom formation is not solely to aid in, nor is it necessarily a result of, bacterial growth. Watersoaking is caused by most xanthomonads and it is thought to contribute to bacterial dissemination (Brunings and Gabriel 2003). Mutation of Tal $g$ in X. oryzae pv. oryzicola and AvrB6 in X. campestris pv. malvacearum resulted in decreased bacterial exudation from the leaf surface, a phenotype that was attributed to the decreased watersoaking conferred by the mutant strains. Notably, neither Tal2g nor AvrB6 directly promote bacterial growth (Cernadas et al. 2014; Yang et al. 1994). AtSWEET9, a clade III SWEET sucrose uniporter from Arabidopsis thaliana, was recently shown to be involved in nectar secretion. AtSWEET9 exports sucrose into the apoplasm, where it is likely broken down into hexose sugars by a plant invertase, thereby maintaining a sufficient osmotic gradient for water secretion (Lin et al. 2014). An intriguing possibility is that MeSWEET10a aids bacterial growth by providing an apoplastic carbon source and independently promotes water accumulation by altering the osmotic gradient of 
the mesophyll, leading to $X$. axonopodis pv. manihotis's characteristic watersoaking symptoms.

The identification of $X$. axonopodis pv. manihotis-induced susceptibility genes will contribute to developing cassava that is resistant to CBB. Li and colleagues (2012) reported an experiment in rice in which TAL effector nucleases were used to generate promoter mutations that abolished TAL effector induction of downstream susceptibility genes, resulting in $X$. oryzae pv. oryzae-resistant rice. This type of resistance strategy will prove effective in cassava if targeting of a given susceptibility gene promoter is a conserved strategy among $X$. axonopodis pv. manihotis strains. Although we were previously able to shed light on effector conservation across a collection of $X$. axonopodis pv. manihotis isolates using next-generation sequencing, this type of work applied to TAL effectors remains complicated because of their highly repetitive sequences. We considered a panel of diverse $X$. axonopodis pv. manihotis strains for induction of MeSWEET1Oa, and found activation to be conserved in nine of 11 strains and correlated with the presence with a TAL20 ${ }_{\text {Xam668 }}$-sized TAL effector. Our results suggest that an effective resistance strategy against CBB would be one that abolishes the ability of $X$. axonopodis pv. manihotis to induce MeSWEET10a; however, additional susceptibility genes must be identified to ensure resistance. Multiple X. oryzae pv. oryzae TAL effector-targeted SWEET susceptibility genes have been identified; therefore, it is possible that the $X$. axonopodis pv. manihotis strains that do not activate MeSWEET1Oa target a different yet functionally equivalent member of the cassava SWEET family (Antony et al. 2010; Liu et al. 2011). We propose that a combination of identifying plant resistance genes that recognize members of a core set of effectors coupled with the genome editing of cassava susceptibility gene promoters will provide a multipronged strategy that will hinder pathogen growth and reduce the possibility of selecting for mutants that can overcome disease resistance. This approach should provide a durable resistance in the host, saving farmers from the hardships associated with crop loss (Dangl et al. 2013).

\section{MATERIALS AND METHODS}

Additional methods are provided in Supplementary Text.

\section{Plant inoculations and virulence assays.}

Xanthomonas strains were resuspended in $10 \mathrm{mM} \mathrm{MgCl}_{2}$. For watersoaking assays and inoculations for semiquantitative RT-PCR, abaxial nicks were made on leaves of cassava 60444 with a razor blade and culture was injected into the leaf via a 1-ml needleless syringe. For midvein growth assays, 2-mm holes were made with a glass Pasteur pipette in the midvein one-quarter of the way in from the leaf tip. A 5- $\mu 1$ drop of bacterial suspension at an optical density at $600 \mathrm{~nm}\left(\mathrm{OD}_{600}\right)=0.2$ was immediately placed in the hole and allowed to dry undisturbed for $15 \mathrm{~min}$. At each time point, 3 -cm midvein sections starting $0.5 \mathrm{~cm}$ in from the inoculation point were cut out and ground in $10 \mathrm{mM} \mathrm{MgCl} 2$ with a $3-\mathrm{mm}$ glass bead in a beadbeater. Two midvein sections were combined per replicate, for a total of three replicates. Serial dilutions were plated on the appropriate selection plus CHX to inhibit fungal growth.

\section{RNA-Seq.}

Strain construction for RNA-Seq. X. euvesicatoria (TAL20 Xam668) was made by conjugating a cosmid library clone (pLAFR3) containing TAL20 Xam668 into X. euvesicatoria 85-10 by triparental mating, using Escherichia coli helper strain pRK600. Expression of TAL20 Xam668 was verified by Western blot.
Plant inoculations for RNA-Seq. X. axonopodis pv. manihotis and $X$. euvesicatoria grown on nutrient yeast glycerol agar plates supplemented with rifampicin $(100 \mu \mathrm{g} / \mathrm{ml})$ or rifampicin and tetracycline $(10 \mu \mathrm{g} / \mathrm{ml})$ for $X$. euvesicatoria(TAL20 Xam668 $)$ were resuspended in $10 \mathrm{mM} \mathrm{MgCl} 2$ at $\mathrm{OD}_{600}=0.5$. Abaxial nicks were made on leaves of cassava 60444 with a razor blade and culture was injected into the leaf via a 1-ml needleless syringe. Mock infiltrations were done with $10 \mathrm{mM} \mathrm{MgCl}$.

NGS library preparation. Total RNA from inoculated leaf tissue (30 to $50 \mathrm{mg}$ ) was extracted with the Spectrum Plant total RNA kit (Sigma-Aldrich), with an on-column DNaseI digestion step included. RNA quality was checked by Bioanalyzer (RNA pico chip; Functional Genomics Laboratory [FGL], University of California [UC] Berkeley). RNA-Seq libraries were made using the TruSeq RNA sample preparation kit (v2; Illumina), starting with $3 \mu \mathrm{g}$ of total RNA. Library quality was assessed by Bioanalyzer (DNA 1000 chip; FGL, UC Berkeley). Quantification by quantitative PCR and pooling of samples was carried out at UC Berkeley's Genomics Sequencing Laboratory (GSL). Libraries were sequenced at the GSL on an Illumina HiSeq 2000, generating 100-bp paired-end reads. Raw reads were submitted to Short Read Archive (BioProject: PRJNA257332).

Data analysis. Raw read files were trimmed for quality and adaptor removal using Trimmomatic (LEADING:3 TRAILING:3 SLIDINGWINDOW:4:15 MINLEN:36) (Lohse et al. 2012). After trimming, gene expression changes were identified using the Tuxedo suite of tools with the default setting (Trapnell et al. 2012). In brief, bowtie-build was used to make a bowtie index from the only publicly available and annotated cassava genome, AM560-2 v 4.1, available from Phytozome (Prochnik et al. 2012). TOPHAT (-I 1000-i20) was used to align reads to identify gene models, map reads to gene models, and estimate expression levels. Analyses were first conducted individually on three biological replicates and global gene expression patterns were examined using the R-implementation CummeRbund (Trapnell et al. 2012) to identify outlying biological replicates. Because all three replicates had similar expression profiles, final analysis was conducted on the union of all three biological replicates for increased statistical power. Cufflinks was run with default settings on the "accepted hits" bam files from the TOPHAT analysis. Cuffmerge was used to join all gene models from all Cufflinks analyses and then Cuffdiff was used to estimate differential gene expression values. By default, Cuffdiff analyzes all possible combinations of input conditions. In-house python scripts were used to pare data down to comparisons of mock versus Xam668 and X. euvesicatoria 85-10 versus X. euvesicatoria(TAL20) for each time point. Comparisons that showed at least threefold induction at one time point were chosen for further consideration. In addition, comparisons that yielded nonstatistically significant data were excluded. A heat map of the resulting list was generated to compare expression patterns across all samples. Rows that showed highly variable or inconsistent trends in expression were excluded.

Prediction of Xam668 TALE-targeted EBE. TALE-NT was used to identify potential binding sites in the cassava promoterome (1 kb upstream of annotated start codons) for Xam668 TAL effectors (Doyle et al. 2012). Each TAL effector was assigned a best binding score given its RVD sequence, and sites within a threefold cut-off of this score were considered potential EBE. Functional annotations for each gene model were obtained from the Mesculenta_147_annotation_info text file (last modified 12.26.12) available from Phytozome.

\section{Semiquantitative RT-PCR analysis.}

$X$. axonopodis pv. manihotis strains were inoculated as described at $\mathrm{OD}_{600}=0.5$. Total RNA was extracted with the 
Spectrum plant total RNA kit (Sigma-Aldrich), with an on-column DNaseI digestion step included. Starting with $1 \mu \mathrm{g}$ of total RNA, cDNA was made using the SuperScript III firststrand synthesis system for RT-PCR (Invitrogen) and diluted 1:10. The $25-\mu \mathrm{l}$ RT-PCR reactions contained $10 \mu \mathrm{l}$ of the diluted cDNA sample, $0.2 \mu \mathrm{M}$ forward primer, $0.2 \mu \mathrm{M}$ reverse primer, and $1 \times$ OneTaq Master Mix with Standard Buffer (New England Biolabs). Reactions cycled 25 times (unless otherwise stated in figure legends) and were run on high percent Tris-acetate-EDTA agarose gels. For CHX treatments, bacterial infiltrations were done with suspensions containing $50 \mu \mathrm{M}$ CHX. Actin (gene ID cassava4.1_009807) was used as a control for all RT-PCR. Primer sequences can be found in Supplementary Table 3.

\section{$N$. benthamiana transient expression analyses.}

Leaves of $N$. benthamiana were injected with Agrobacterium tumefaciens GV3101 suspensions $\left(\mathrm{OD}_{600}=0.4\right)$ using a $1-\mathrm{ml}$ needleless syringe. At $24 \mathrm{hpi}$, sites of Agrobacterium inoculation were infiltrated with $1 \mathrm{mM}$ luciferin. For each site, four 0.28 $\mathrm{cm}^{2}$ leaf punches were taken and placed in separate wells of a black microtiter plate, suspended on $100 \mu \mathrm{l}$ of water. Luciferase activity was read using a Wallace Envision machine.

\section{Construction of dTALE and complemented strains.}

The DNA binding domain of dTALE were assembled as described by Morbitzer and associates (2010) and used to replace the RVD of AvrBs3. We designed two distinct dTALE with MeSWEET1O promoter-specific, code-optimized RVD

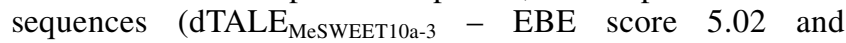

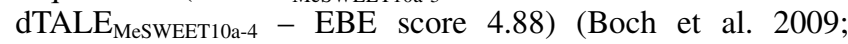
Moscou and Bogdanove 2009). No dTALE target sites overlap with validated TAL20 ${ }_{\text {Xam668 }}$ EBE. For both dTALE, the ratio of the EBE score to the hypothetical best possible score is 1 . dTALE constructs driven by the TAL2O Xam668 promoter in pVSP61 were conjugated into Xam668DTAL20 using E. coli helper strain pRK600.

\section{Characterization of SuxC mutant.}

$X$. axonopodis pv. manihotis strains were grown in a $28^{\circ} \mathrm{C}$ shaker in $20 \mathrm{ml}$ of minimal MME medium $\left(\mathrm{K}_{2} \mathrm{HPO}_{4}, 10.5\right.$ g/liter; $\mathrm{KH}_{2} \mathrm{PO}_{4}, 4.5 \mathrm{~g} /$ liter; $\left(\mathrm{NH}_{4}\right)_{2} \mathrm{SO}_{4}, 1 \mathrm{~g} /$ liter; $\mathrm{MgSO}_{4}, 1 \mathrm{mM}$; casamino acids, $0.15 \mathrm{~g} / \mathrm{liter}$ ) (Arlat et al. 1991) containing 20 $\mathrm{mM}$ sucrose or glucose and rifampicin $(100 \mu \mathrm{g} / \mathrm{ml})$. Following inoculation at $\mathrm{OD}_{600}=0.1$ from a washed starter culture, optical densities at $600 \mathrm{~nm}$ were measured every 10 to $20 \mathrm{~h}$ over a period of $100 \mathrm{~h}$.

\section{FRET analysis.}

Mammalian cell culture, transfection, image acquisition, and FRET analysis were performed essentially as described (Hou et al. 2011; Takanaga and Frommer 2010). In short, HEK293T cells were grown in DMEM (Invitrogen) with $10 \%$ fetal bovine serum, penicillin at $50 \mathrm{U} / \mathrm{ml}$, and streptomycin at $50 \mu \mathrm{g} / \mathrm{ml}$ in a $37^{\circ} \mathrm{C}$ incubator at $5 \% \mathrm{CO}_{2}$. For FRET imaging, cells were cultured on collagen-coated glass cover slips. Cells were transfected when the confluence of cells reached 35 to $40 \%$. FLIPsuc $90 \mu \Delta 1$ a (a FRET sucrose sensor modified from FLIPsuc $90 \mu$ [Lager et al. 2006] carrying full eCFP at the $\mathrm{N}$ terminus and Aphrodite [Deuschle et al. 2006] at its C terminus) in pcDNA3.1(-) and FLII ${ }^{12}$ Pglu700 $\mu \vartheta 6$ in pcDNA3.1(-) (Takanaga et al. 2008) were used to monitor sucrose and glucose uptake activities, respectively.

\section{Western analysis.}

Minimal media expression and protein extraction. Overnight liquid cultures of $X$. axonopodis pv. manihotis were resus- pended in $125 \mu \mathrm{l}$ of minimal media $\mathrm{A}$ ( $\mathrm{pH}$ 5.14) to $\mathrm{OD}_{600}=0.2$ along with appropriate antibiotics-X. axonopodis pv. manihotis strains: rifampicin $(100 \mu \mathrm{g} / \mathrm{ml}), \Delta$ TALE rifampicin $(100 \mu \mathrm{g} / \mathrm{ml})$, and tetracycline $(10 \mu \mathrm{g} / \mathrm{ml})$ and Xam668 $\Delta$ TALE(pVSP61 TALE): rifampicin $(100 \mu \mathrm{g} / \mathrm{ml})$, tetracycline $(10 \mu \mathrm{g} / \mathrm{ml})$, and kanamycin $(25 \mu \mathrm{g} / \mathrm{ml})$ — and shaken at $28^{\circ} \mathrm{C}$ for $4 \mathrm{~h}$. An equal volume of $3 \times$ Laemmli buffer was added and samples were boiled $6 \mathrm{~min}$, vortexed, spun down, and stored as aliquots at $-80^{\circ} \mathrm{C}$.

Western blot. Protein lysates were separated via sodium dodecyl sulfate polyacrylamide gel electrophoresis (SDS-PAGE) using the NuPAGE Novex 4 to $12 \%$ Bis-Tris precast gels in NuPAGE morpholinepropanesulfonic acid SDS running buffer (Life Technologies). After $4.5 \mathrm{~h}$ at $120 \mathrm{~V}$, TAL effector content was analyzed using standard immunoblotting techniques with a polyclonal antibody capable of recognizing diverse TAL effectors. Full-length PthB, renamed TALE1 $1_{\text {Xam }}$ (Castiblanco et al. 2013), was expressed in E. coli from the vector pETDuet, which added a C-terminal $6 x$ His tag. TALE1 $1_{\text {Xam }}$ protein was purified on a nickel column and sent to Covance for antibody production in rabbit.

\section{ACKNOWLEDGMENTS}

We thank D. Sosso for phylogenetic analysis aimed at naming cassava SWEET transporters and L. Pachter for guidance with RNA-Seq data analysis. This work was funded by the National Science Foundation (NSF) Basic Research to Enable Agricultural Development (grant 0965418, to B. J. Staskawicz), National Institute of Food and Agriculture (grant 10708051, to R. S. Bart), NSF Graduate Research Fellowship (to M. Cohn and M. Shybut), National Institutes of Health Genetics Training Grant 2T32GM007127-36A1 (to M. Cohn), NSF Louis Stokes Alliances for Minority Participation Bridge Doctoral Fellowship (grant 1249249, to M. Gomez), the Bill \& Melinda Gates Foundation through the Grand Challenges Exploration Initiative (to B.-H. Hou and W. B. Frommer), and funds from the NSF (NSF-IOS 1258018, to W. B. Frommer). This work used the Vincent J. Coates Genomics Sequencing Laboratory at University of California Berkeley, supported by NIH S10 Instrumentation Grants S10RR029668 and S10RR027303. M. Cohn, R. S. Bart, and B. J. Staskawicz designed research; M. Cohn, R. S. Bart, M. Shybut, M. Gomez, D. Dahlbeck, B. Hou, and R. Morbitzer performed research; M. Cohn, R. S. Bart, W. B. Frommer, T. Lahaye, and B. J. Staskawicz analyzed data; M. Cohn, R. S. Bart, and B. J. Staskawicz wrote the paper; W. B. Frommer and T. Lahaye provided critical reading of the manuscript.

\section{LITERATURE CITED}

Antony, G., Zhou, J., Huang, S., Li, T., Liu, B., White, F., and Yang, B. 2010. Rice xa13 recessive resistance to bacterial blight is defeated by induction of the disease susceptibility gene Os-11N3. Plant Cell 22:3864-3876.

Arlat, M., Gough, C., Barber, C., Boucher, C., and Daniels, M. 1991. Xanthomonas campestris contains a cluster of hrp genes related to the larger hrp cluster of Pseudomonas solanacearum. Mol. Plant-Microbe Interact. 4:593-601.

Arrieta-Ortiz, M. L., Rodríguez-R, L. M., Pérez-Quintero, Á. L., Poulin, L., Díaz, A. C., Arias Rojas, N., Trujillo, C., Restrepo Benavides, M., Bart, R., Boch, J., Boureau, T., Darrasse, A., David, P., Dugé de Bernonville, T., Fontanilla, P., Gagnevin, L., Guérin, F., Jacques, M.-A., Lauber, E., Lefeuvre, P., Medina, C., Medina, E., Montenegro, N., Muñoz Bodnar, A., Noël, L. D., Ortiz Quiñones, J. F., Osorio, D., Pardo, C., Patil, P. B., Poussier, S., Pruvost, O., Robène-Soustrade, I., Ryan, R. P., Tabima, J., Urrego Morales, O. G., Vernière, C., Carrere, S., Verdier, V., Szurek, B., Restrepo, S., López, C., Koebnik, R., and Bernal, A. 2013. Genomic survey of pathogenicity determinants and VNTR markers in the cassava bacterial pathogen Xanthomonas axonopodis pv. manihotis strain CIO151. PLoS One 8:e79704. Published online.

Bai, J., Choi, S. H., Ponciano, G., Leung, H., and Leach, J. E. 2000. Xanthomonas oryzae pv. oryzae avirulence genes contribute differently and specifically to pathogen aggressiveness. Mol. Plant-Microbe Interact. 13:1322-1329.

Bart, R., Cohn, M., Kassen, A., McCallum, E. J., Shybut, M., Petriello, A., Krasileva, K., Dahlbeck, D., Medina, C., Alicai, T., Kumar, L., Moreira, 
L. M., Rodrigues Neto, J., Verdier, V., Santana, M. A., Kositcharoenkul, N., Vanderschuren, H., Gruissem, W., Bernal, A., and Staskawicz, B. J. 2012. High-throughput genomic sequencing of cassava bacterial blight strains identifies conserved effectors to target for durable resistance. Proc. Natl. Acad. Sci. U.S.A. 109:E1972-9.

Bart, R., Cohn, M., Kassen, A., McCallum, E. J., Shybut, M., Petriello, A., Krasileva, K., Dahlbeck, D., Medina, C., Alicai, T., Kumar, L., Moreira, L. M., Rodrigues Neto, J., Verdier, V., Santana, M. A., Kositcharoenkul, N., Vanderschuren, H., Gruissem, W., Bernal, A., and Staskawicz, B. J. 2013. Erratum. High-throughput genomic sequencing of cassava bacterial blight strains identifies conserved effectors to target for durable resistance. Proc. Natl. Acad. Sci. U.S.A. 110:19969.

Blanvillain, S., Meyer, D., Boulanger, A., Lautier, M., Guynet, C., Denancé, N., Vasse, J., Lauber, E., and Arlat, M. 2007. Plant carbohydrate scavenging through tonB-dependent receptors: A feature shared by phytopathogenic and aquatic bacteria. PLoS One 2:e224. Published online.

Boch, J., and Bonas, U. 2010. Xanthomonas campestris AvrBs3 familytype III effectors: Discovery and function. Annu. Rev. Phytopathol. 48:419-436.

Boch, J., Scholze, H., Schornack, S., Landgraf, A., Hahn, S., Kay, S., Lahaye, T., Nickstadt, A., and Bonas, U. 2009. Breaking the code of DNA binding specificity of TAL-type III effectors. Science 326:15091512.

Bogdanove, A. J., Schornack, S., and Lahaye, T. 2010. TAL effectors: Finding plant genes for disease and defense. Curr. Opin. Plant Biol. 13:394-401.

Boher, B., Kpemoua, K., Nicole, M., Luisetti, J., and Geiger, J. 1995. Ultrastructure of interactions between cassava and Xanthomonas campestris pv. manihotis: Cytochemistry of cellulose and pectin degradation in a susceptible cultivar. Phytopathology 85:777-788.

Brencic, A., and Winans, S. 2005. Detection of and response to signals involved in host-microbe interactions by plant-associated bacteria. Microbiol. Mol. Biol. Rev. 69:155-194.

Brunings, A., and Gabriel, D. 2003. Xanthomonas citri: Breaking the surface. Mol. Plant Pathol. 4:141-157.

Bull, S., Owiti, J., Niklaus, M., Beeching, J., Gruissem, W., and Vanderschuren, H. 2009. Agrobacterium-mediated transformation of friable embryogenic calli and regeneration of transgenic cassava. Nat. Protocols 4:1845-1854.

Bultmann, S., Morbitzer, R., Schmidt, C. S., Thanisch, K., Spada, F., Elsaesser, J., Lahaye, T., and Leonhardt, H. 2012. Targeted transcriptional activation of silent oct 4 pluripotency gene by combining designer TALEs and inhibition of epigenetic modifiers. Nucleic Acids Res. 40:5368-5377.

Castiblanco, L. F., Gil, J., Rojas, A., Osorio, D., Gutiérrez, S., MuñozBodnar, A., Perez-Quintero, A. L., Koebnik, R., Szurek, B., López, C., Restrepo, S., Verdier, V., and Bernal, A. J. 2013. TALE1 from Xanthomonas axonopodis pv. manihotis acts as a transcriptional activator in plant cells and is important for pathogenicity in cassava plants. Mol. Plant Pathol. 14:84-95.

Cernadas, R. A, Doyle, E. L., Niño-Liu, D. O., Wilkins, K. E., Bancroft, T., Wang, L., Schmidt, C. L., Caldo, R., Yang, B., White, F. F., Nettleton, D., Wise, R. P., and Bogdanove, A. J. 2014. Code-assisted discovery of TAL effector targets in bacterial leaf streak of rice reveals contrast with bacterial blight and a novel susceptibility gene. PLoS Pathog. 10:e1003972. Published online.

Chen, L. 2014. Minireview SWEET sugar transporters for phloem transport and pathogen nutrition. New Phytol. 201:1150-1155.

Chen, L.-Q., Hou, B.-H., Lalonde, S., Takanaga, H., Hartung, M. L., Qu, X.-Q., Guo, W.-J., Kim, J.-G., Underwood, W., Chaudhuri, B., Chermak, D., Antony, G., White, F. F., Somerville, S. C., Mudgett, M. B., and Frommer, W. B. 2010. Sugar transporters for intercellular exchange and nutrition of pathogens. Nature 468:527-532.

Chen, L.-Q., Qu, X.-Q., Hou, B.-H., Sosso, D., Osorio, S., Fernie, A. R., and Frommer, W. B. 2012. Sucrose efflux mediated by SWEET proteins as a key step for phloem transport. Science 335:207-211.

Chu, Z., Yuan, M., Yao, J., Ge, X., Yuan, B., Xu, C., Li, X., Fu, B., Li, Z., Bennetzen, L., Zhang, Q., and Wang, S. 2006. Promoter mutations of an essential gene for pollen development result in disease resistance in rice. Genes Dev. 20:1250-1255.

Dangl, J. L., Horvath, D. M., and Staskawicz, B. J. 2013. Pivoting the plant immune system from dissection to deployment. Science 34:746751

Deng, D., Yan, C., Pan, X., Mahfouz, M., Wang, J., Zhu, J.-K., Shi, Y., and Yan, N. 2012. Structural basis for sequence-specific recognition of DNA by TAL effectors. Science 335:720-723.

Deuschle, K., Chaudhuri, B., Okumoto, S., Lager, I., Lalonde, S., and Frommer, W. B. 2006. Rapid metabolism of glucose detected with FRET glucose nanosensors in epidermal cells and intact roots of
Arabidopsis RNA-silencing mutants. Plant Cell 18:2314-2325.

Doyle, E. L., Booher, N. J., Standage, D. S., Voytas, D. F., Brendel, V. P., Vandyk, J. K., and Bogdanove, A. J. 2012. TAL Effector-Nucleotide Targeter (TALE-NT) 2.0: Tools for TAL effector design and target prediction. Nucleic Acids Res. 40:W117-W122.

FAO. 2008. Cassava. Food and Agriculture Organization of the United Nations. www.fao.org/ag/AGP/agpc/gcds/index_en.html. Published online.

Goodstein, D. M., Shu, S., Howson, R., Neupane, R., Hayes, R. D., Fazo, J., Mitros, T., Dirks, W., Hellsten, U., Putnam, N., and Rokhsar, D. S. 2012. Phytozome: A comparative platform for green plant genomics. Nucleic Acids Res. 40:D1178-D1186.

Hou, B.-H., Takanaga, H., Grossmann, G., Chen, L.-Q., Qu, X.-Q., Jones, A. M., Lalonde, S., Schweissgut, O., Wiechert, W., and Frommer, W. B. 2011. Optical sensors for monitoring dynamic changes of intracellular metabolite levels in mammalian cells. Nat. Protocols 6:1818-1833.

Howeler, R., Lutaladio, N., and Thomas, G. 2013. Save and Grow Cassava: A Guide to Sustainable Production Intensification. FAO Plant Production and Protection Div., Rome.

Hu, Y., Zhang, J., Jia, H., Sosso, D., Li, T., Frommer, W. B., Yang, B., White, F. F., Wang, N., and Jones, J. B. 2014. Lateral organ boundaries 1 is a disease susceptibility gene for citrus bacterial canker disease. Proc. Natl. Acad. Sci. U.S.A. 111:E521-9.

Kay, S., Hahn, S., Marois, E., Hause, G., and Bonas, U. 2007. A bacterial effector acts as a plant transcription factor and induces a cell size regulator. Science 318:648-651.

Kocal, N., Sonnewald, U., and Sonnewald, S. 2008. Cell wall-bound invertase limits sucrose export and is involved in symptom development and inhibition of photosynthesis during compatible interaction between tomato and Xanthomonas campestris pv. vesicatoria. Plant Physiol. 148:1523-1536.

Lager, I., Looger, L. L., Hilpert, M., Lalonde, S., and Frommer, W. B. 2006. Conversion of a putative Agrobacterium sugar-binding protein into a FRET sensor with high selectivity for sucrose. J. Biol. Chem. 281:30875-30883.

Leszczyszyn, O. I., Imam, H. T., and Blindauer, C. A. 2013. Diversity and distribution of plant metallothioneins: A review of structure, properties and functions. Metallomics 5:1146-1169.

Li, T., Liu, B., Spalding, M. H., Weeks, D. P., and Yang, B. 2012. Highefficiency TALEN-based gene editing produces disease-resistant rice. Nat. Biotechnol. 30:390-392

Li, Z., Zou, L., Ye, G., Xiong, L., Ji, Z., Zakria, M., Hong, N., Wang, G., and Chen, G. 2014. A potential disease susceptibility gene CsLOB of Citrus is targeted by a major virulence effector PthA of Xanthomonas citri subsp. citri. Mol. Plant 7:912-915

Lin, I. W., Sosso, D., Chen, L. Q., Gase, K., Kim, S. G., Kessler, D., Klinkenberg, P. M., Gorder, M. K., Hou, B. H., Qu, X. Q., Carter, C. J., Baldwin, I. T., and Frommer, W. B. 2014. Nectar secretion requires sucrose phosphate synthases and the sugar transporter SWEET9. Nature 508:546-549.

Liu, Q., Yuan, M., Zhou, Y., Li, X., Xiao, J., and Wang, S. 2011. A paralog of the MtN3/saliva family recessively confers race-specific resistance to Xanthomonas oryzae in rice. Plant Cell Environ. 34:1958-1969.

Lohse, M., Bolger, A. M., Nagel, A., Fernie, A. R., Lunn, J. E., Stitt, M., and Usadel, B. 2012. RobiNA: A user-friendly, integrated software solution for RNA-Seq-based transcriptomics. Nucleic Acids Res. 40:W622-W627.

López, C., and Bernal, A. 2012. Cassava Bacterial Blight: Using genomics for the elucidation and management of an old problem. Trop. Plant Biol. 5:117-126.

Lozano, J. 1986. Cassava Bacterial Blight: A manageable disease. Plant Dis. 70:1089-1093.

Mak, A., Bradley, P., Cernadas, R., Bogdanove, A. J., and Stoddard, B. L. 2012. The crystal structure of TAL effector PthXo1 bound to its DNA target. Science 335:716-719.

Marois, E., Van den Ackerveken, G., and Bonas, U. 2002. The Xanthomonas campestris type III effector protein AvrBs3 modulates plant gene expression and induces cell hypertrophy in the susceptible host. Mol. Plant-Microbe Interact. 15:637-646.

Morbitzer, R., Römer, P., Boch, J., and Lahaye, T. 2010. Regulation of selected genome loci using de novo-engineered transcription activatorlike effector (TALE)-type transcription factors. Proc. Natl. Acad. Sci. U.S.A. 107:21617-21622.

Moscou, M. J., and Bogdanove, A. J. 2009. A simple cipher governs DNA recognition by TAL effectors. Science 326:1501.

Pérez-Quintero, A. L., Rodriguez-R, L. M., Dereeper, A., López, C., Koebnik, R., Szurek, B., and Cunnac, S. 2013. An improved method for TAL effectors DNA-binding sites prediction reveals functional convergence in TAL repertoires of Xanthomonas oryzae strains. PLoS One 8:e68464. Published online. 
Petersen, T. N., Brunak, S., von Heijne, G., and Nielsen, H. 2011. SignalP 4.0: Discriminating signal peptides from transmembrane regions. Nat. Methods 8:785-786.

Prochnik, S., Marri, P. R., Desany, B., Rabinowicz, P. D., Kodira, C., Mohiuddin, M., Rodriguez, F., Fauquet, C., Tohme, J., Harkins, T., Rokhsar, D. S., and Rounsley, S. 2012. The cassava genome: Current progress, future directions. Trop. Plant Biol. 5:88-94.

Restrepo, S., Veléz, C. M., and Verdier, V. 2000. Measuring the genetic diversity of Xanthomonas axonopodis pv. manihotis within different fields in Columbia. Phytopathology 90:683-690.

Restrepo, S., Velez, C. M., Duque, M. C., and Verdier, V. 2004. Genetic structure and population dynamics of Xanthomonas axonopodis pv. manihotis in Colombia from 1995 to 1999. Appl. Environ. Microbiol. 70:255-261.

Römer, P., Hahn, S., Jordan, T., Strauss, T., Bonas, U., and Lahaye, T. 2007. Plant pathogen recognition mediated by promoter activation of the pepper Bs3 resistance gene. Science 318:645-648.

Römer, P., Recht, S., and Lahaye, T. 2009. A single plant resistance gene promoter engineered to recognize multiple TAL effectors from disparate pathogens. Proc. Natl. Acad. Sci. U.S.A. 106:20526-20531.

Schornack, S., Moscou, M. J., Ward, E. R., and Horvath, D. M. 2013. Engineering plant disease resistance based on TAL effectors. Annu. Rev. Phytopathol. 51:383-406.

Sonnewald, U. 2011. Sweets-the missing sugar efflux carriers. Front Plant Sci. 2:1-2

Streubel, J., Pesce, C., Hutin, M., Koebnik, R., Boch, J., and Szurek, B. 2013. Five phylogenetically close rice SWEET genes confer TAL effector mediated susceptibility to Xanthomonas oryzae pv. oryzae. New Phytol. 200:808-819.

Sturm, A. 1999. Invertases. Primary structures, functions, and roles in plant development and sucrose partitioning. Plant Physiol. 121:1-7.

Swarup, S., De Feyter, R., Brlansky, R., and Gabriel, D. 1991. A pathogenicity locus from Xanthomonas citri enables strains from several pathovars of $X$. campestris to elicit cankerlike lesions on citrus. Phytopathology 81:802-809.

Takanaga, H., and Frommer, W. B. 2010. Facilitative plasma membrane transporters function during ER transit. FASEB (Fed. Am. Soc. Exp. Biol.) J. 24:2849-2858

Takanaga, H., Chaudhuri, B., and Frommer, W. B. 2008. GLUT1 and GLUT9 as major contributors to glucose influx in HepG2 cells identified by a high sensitivity intramolecular FRET glucose sensor. Biochim. Biophys. Acta Biomembranes 1778:1091-1099.

Tamura, K., Peterson, D., Peterson, N., Stecher, G., Nei, M., and Kumar, S. 2011. MEGA5: Molecular evolutionary genetics analysis using maximum likelihood, evolutionary distance, and maximum parsimony methods. Mol. Biol. Evol. 28:2731-2739.

Trapnell, C., Roberts, A., Goff, L., Pertea, G., Kim, D., Kelley, D. R., Pimentel, H., Salzberg, S. L., Rinn, J. L., and Pachter, L. 2012. Differential gene and transcript expression analysis of RNA-seq experiments with TopHat and Cufflinks. Nat. Protocols 7:562-578.

Verdier, V., Triplett, L., Hummel, A., Corral, R., Cernadas, R., Schmidt, C., Bogdanove, A. J., and Leach, J. 2012. Transcription activator-like (TAL) effectors targeting OsSWEET genes enhance virulence on diverse rice (Oryza sativa) varieties when expressed individually in a TAL effector-deficient strain of Xanthomonas oryzae. New Phytol. 196:1197-1207.

Vogel, J. P., Raab, T. K., Schiff, C., and Somerville, S. C. 2002. PMR6, pectate lyase-like gene required for powdery mildew susceptibility in Arabidopsis. Plant Cell 14:2095-2106.

Wydra, K., Zinsou, V., Jorge, V., and Verdier, V. 2004. Identification of pathotypes of Xanthomonas axonopodis pv. manihotis in Africa and detection of QTLs and markers for resistance to bacterial blight of cassava. Phytopathology 94:1084-1093.

Yang, B., and White, F. F. 2004. Diverse members of the AvrBs3/PthA family of type III effectors are major virulence determinants in bacterial blight disease of rice. Mol. Plant-Microbe Interact. 17:1192-1200.

Yang, B., Sugio, A., and White, F. F. 2006. Os8N3 is a host disease-susceptibility gene for bacterial blight of rice. Proc. Natl. Acad. Sci. U.S.A. 103:10503-10508.

Yang, Y., De Feyter, R., and Gabriel, D. 1994. Host-specific symptoms and increased release of Xanthomonas citri and X. campestris pv. malvacearum from leaves are determined by the 102-bp tandem repeats of $p t h A$ and $a v r b 6$, respectively. Mol. Plant-Microbe Interact. 7:345-355.

Yang, Y., Yuan, Q., and Gabriel, D. 1996. Watersoaking function(s) of $\mathrm{XcmH} 1005$ are redundantly encoded by members of the Xanthomonas avr/pth gene family. Mol. Plant-Microbe Interact. 9:105-113.

Yu, Y., Streubel, J., Balzergue, S., Champion, A., Boch, J., Koebnik, R., Feng, J., Verdier, V., and Szurek, B. 2011. Colonization of rice leaf blades by an African strain of Xanthomonas oryzae pv. oryzae depends on a new TAL effector that induces the rice nodulin-3 Os $11 \mathrm{~N} 3$ gene. Mol. Plant-Microbe Interact. 24:1102-1113.

Yuan, M., and Wang, S. 2013. Rice MtN3/saliva/SWEET family genes and their homologues in cellular organisms. Mol. Plant. 6:665-674.

\section{AUTHOR-RECOMMENDED INTERNET RESOURCE}

Phytozome website: www.phytozome.net 